\title{
Thoracoscopic electrocautery-based bidirectional S9-10 segmentectomy
}

\author{
Min Zhang, Qing-Chen Wu, Ming-Jian Ge \\ Department of Cardiothoracic Surgery, the First Affiliated Hospital of Chongqing Medical University, Chongqing 400016, China \\ Correspondence to: Ming-Jian Ge. Department of Cardiothoracic Surgery, the First Affiliated Hospital of Chongqing Medical University, Chongqing \\ 400016, China. Email: doctor1984@sina.com.
}

Submitted Oct 15, 2019. Accepted for publication Jan 18, 2020.

doi: $10.21037 /$ tcr.2020.02.01

View this article at: http://dx.doi.org/10.21037/tcr.2020.02.01

\section{Introduction}

Segmentectomies for the lateral basal segment (S9), posterior basal segment (S10), or both are considered most difficult anatomical segmentectomies (1). They are located deep in the lung parenchyma, far from the interlobar fissure. Besides, the intersegmental plane is cuboid-shaped, making it difficult to fold into a two-dimensional plane by stapler. To solve this problem, several different strategies were proposed. One is the "intersegmental tunnelling" method (2). It features by separating superior (S6) and basal segments first by constructing a tunnel between S6 and S10. This method could be helpful for sufficient dissection of $\mathrm{A} 9 / 10$ and B9/10; however, it results in complete separation of S6 and S8. Possible torsion of the remaining S6 after complete separation is a big concerning. Another strategy is posterior approach or pulmonary ligament (PL) approach, which tracks the anatomy from the pulmonary vein. This method has also its shortcomings: first, a good exposure of pulmonary artery and bronchus is difficult, sometimes resulting confusion. Besides, compared to conventional procedures from the interlobar fissure, this method carries a greater risk of incomplete lymph node dissection.

To overcome the difficulties and to achieve satisfactory surgical outcomes, we herein report the thoracoscopic electrocautery-based bidirectional S9-10 segmentectomy.

\section{Technique}

The positional relations of vessels and bronchus in basal segmental were preoperatively identified by high-resolution computed tomography (HRCT). The main utility incision and observing port was made in the fourth and seventh intercostal space in anterior axillary line. Two assistant incisions were made in the seventh intercostal space in midaxillary line and ninth intercostal space in posterior axillary line.

The bidirectional S9-10 segmentectomy is started from the interlobar fissure, where an adequate dissection is required to obtain correct orientation of pulmonary artery. A6 and A8 are usually easily identified. The target segment artery (A9 or 10) and their branches are located deep in the lung and was dissected and transected. The hilar lymph nodes are resected for intraoperative frozen section examination. If metastases are confirmed, the procedure is converted to lobectomy. This step is of great importance, because removal of hilar lymph nodes is critical not only for lymph node sampling but also for exposure of clean anatomy. Then, the target segmental bronchus is identified according to its running direction and relations with artery stump. It is dissected, but not transected. A sling is passed to encircle the target segment bronchus. This maneuver helps to visualize the target bronchus from PL approach. Resection of target bronchus can be done later from the PL approach (Figure 1).

In the second step, we move to the PL region. This is why we call it "bidirection". The inferior pulmonary vein and its branches are exposed. Unlike Sato (3) who examines the target vein branching by preoperative 3D images, we identify the target V9/10 according to its position and relation with the encircled target segmental bronchus, which acts like a landmark at this stage. A major shortcoming of the posterior approach alone is that the unidirectional dissection of vein sometimes leads 

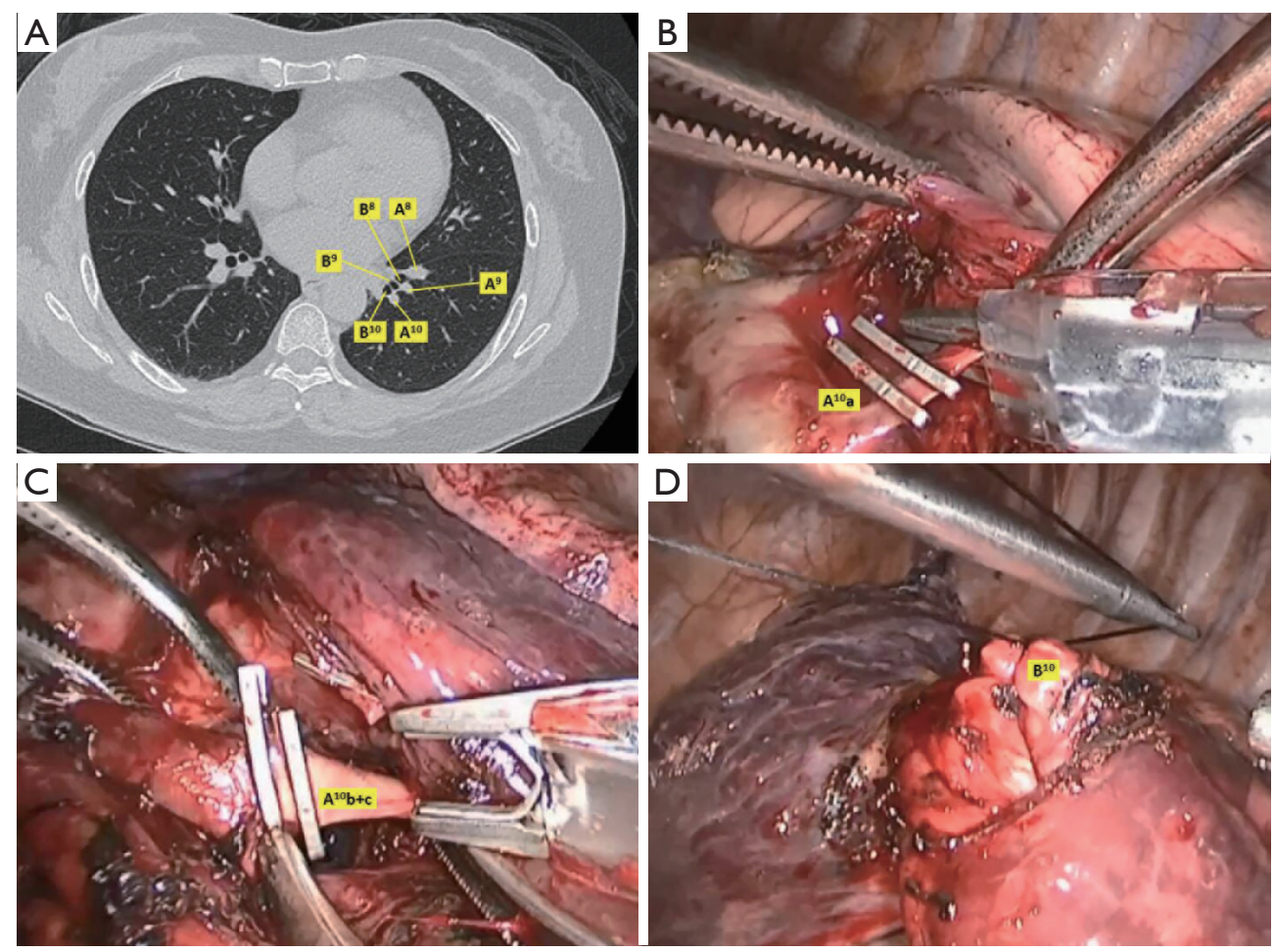

Figure 1 The method of bidirectional left S10 segmentectomy: step 1, the interlobar fissure approach. (A) Identifying the positional relations of the target segmental bronchus and artery on HRCT. (B) Dissecting and transecting the $\mathrm{A}^{10}$ a. (C) Dissecting and transecting the $\mathrm{A}^{10} \mathrm{~b}+\mathrm{c}$. (D) Identifying $\mathrm{B}^{10}$, a sling is passed to encircle it as a landmark. HRCT, high-resolution computed tomography.

the surgeon to misunderstand the anatomy. The V9/10 is transected by endoscopic clips. At last, the confirmed bronchus was transected by stapler (Figure 2).

The inflation-deflation method was used to identify the intersegmental plain. Then, an electrocautery-based three-dimensional tailoring was performed along the intersegmental veins. The recommended principle of stapling is "centrally to peripherally" stapling, which starts from the most difficult hilar thick lung to peripheral, thin parts of the lung in a step-by-step manner (Figure 3).

Between January 2019 and July 2019, 12 patients of segmentectomy of S9-10 were performed. Eleven had lung cancer and 1 had metastasis. The median blood loss was $100 \mathrm{~mL}$ (range, $80-150 \mathrm{~mL}$ ). The median operative time was 128 minutes (range, 82-150 minutes). The median chest tube duration was 3 days (range, 2-6 days). The median postoperative hospital stay was 4 days (range, $3-8$ days). Postoperative morbidity was $8.3 \%$ (1/12). One patient had prolonged air leakage (more than 5 days). No mortality was identified.

\section{Comments}

The bidirectional approach was first proposed by Sato in 2018 (3). It allows for correct understanding of the patient's hilar anatomy from the posterior hilum without separating S6 and basal segments. It is technically easier, especially for surgeons without much experience. However, there are still many differences between Sato's method and ours'. First, they use preoperative 3D images to identify the target structures. It is time-consuming, and not absolutely necessary. From the preoperative HRCT, we can identify clearly the basal segmental bronchus, the number of its branches, and the relative locations of them. Since the belonging artery is running always along the bronchus, it can also be easily identified. Secondly, in Sato's method, the target segmental bronchus was transected from the interlobar fissure. However, we just encircle it as a landmark while the resection of it was left later from the PL region, where the encircled bronchus is helpful for identifying the target vein running along the target bronchus. The identification of target vein is a difficult 

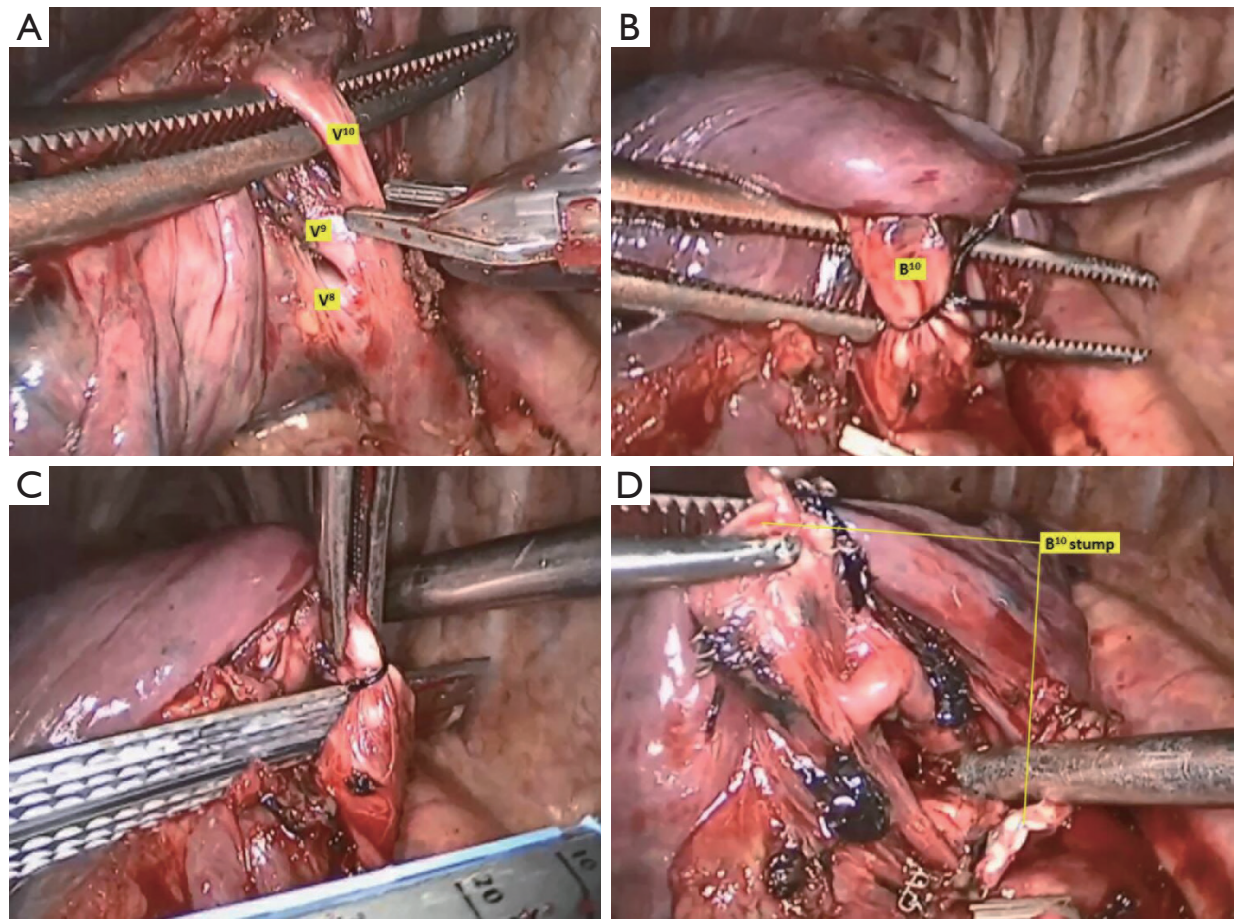

Figure 2 The method of bidirectional left S10 segmentectomy: step 2, the pulmonary ligament approach. (A) Identifying and transecting the $\mathrm{V}^{10}$. (B) Dissecting and re-confirming the $\mathrm{B}^{10}$. (C) Stapling the $\mathrm{B}^{10}$. (D) $\mathrm{B}^{10}$ stump.
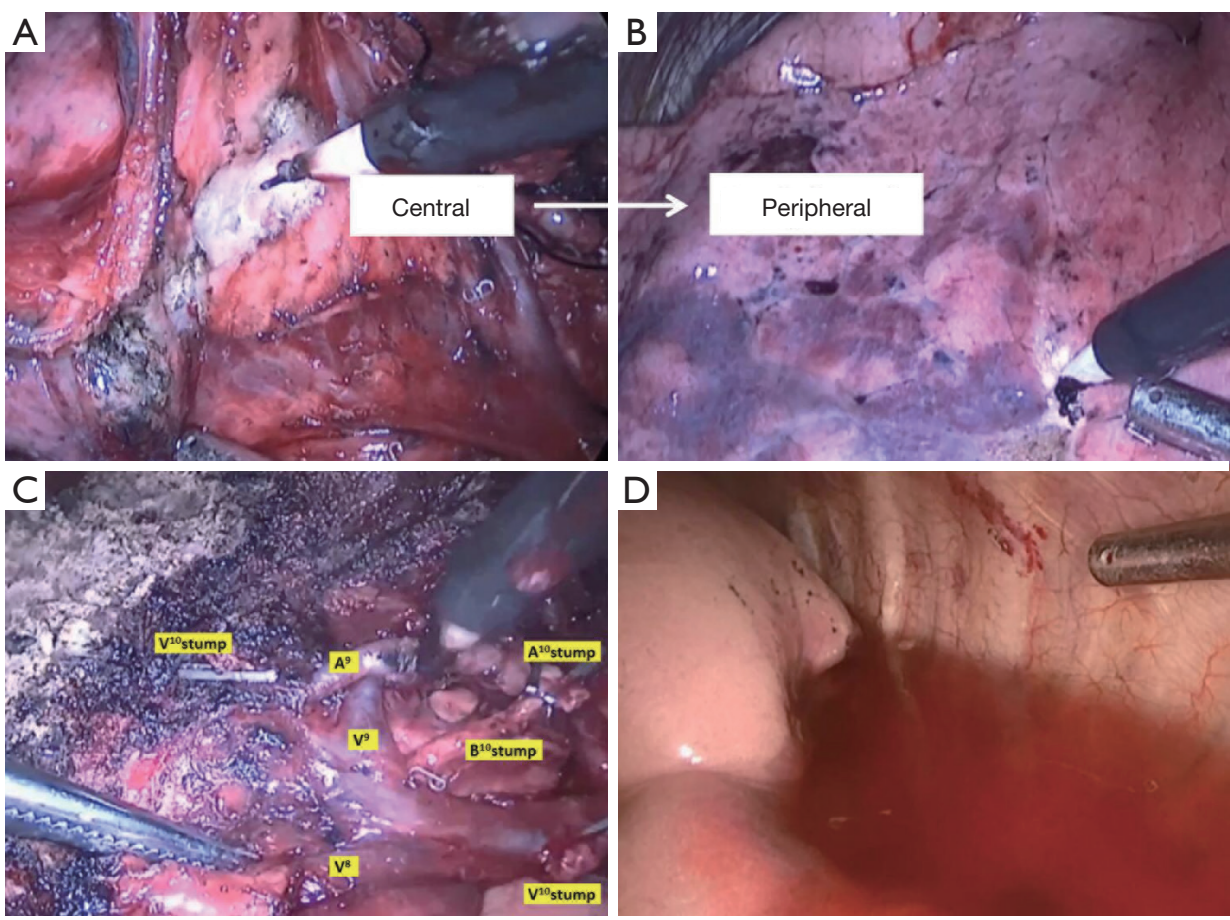

Figure 3 Electrocautery-based three-dimensional tailoring of intersegmental plane. (A) Tailoring starts from the hilar, thick lung tissue (central). (B) Continued tailoring to thin, easy parts of the lung (peripheral). (C) S10 segmentectomy completed. (D) No air leakage at inflation. 
point in S9-10 segmentectomy in PL approach alone, since we cannot get a whole picture of the branches of the inferior pulmonary vein. The bidirectional approach provides a good solution for this problem. Thirdly, Sato's method for the intersegmental plain was a complete staplerbased tailoring and constructing a tunnel by stapler in the parenchyma between S6 and S10. In our method, the intersegmental plain is electrocautery-based tailing starting from the hilum. The electrocautery-based tailoring has its advantage especially in the hilum, where placing the stapler to the hilum can easily damage the lung parenchyma or vessels. This is also why they begin to tailoring from the peripheral, thin parts of the lung. However, in this sequence the peripheral pulmonary artery, bronchus and vein (especially the branches of intersegmental veins) can't be visualized, and were stapled blindly. In our electrocauterybased tailoring, we start centrally from the most difficult hilar thick lung tissue. The stem of intersegmental veins can be clearly identified. During "centrally to peripherally" tailoring, the branches of intersegmental vein are gradually exposed and carefully preserved. Our data indicates that the electrocautery-based bidirectional approach takes no more risks of bleeding and air leakage compared to the PL approach (4).

In conclusion, the bidirectional approach allows for anatomical identification from the fissure, and electrocauterybased resection of the target segment from the posterior hilum. It might be a useful strategy for thoracoscopic S9-10 segmentectomy with acceptable safety and complications.

\section{Acknowledgments}

Funding: None.

\section{Footnote}

Provenance and Peer Review: This article was commissioned by the editorial office, Translational Cancer Research. The article did not undergo external peer review.

Conflicts of Interest: All authors have completed the ICMJE uniform disclosure form (available at http://dx.doi. org/10.21037/tcr.2020.02.01). The authors have no conflicts of interest to declare.

Ethical Statement: The authors are accountable for all aspects of the work in ensuring that questions related to the accuracy or integrity of any part of the work are appropriately investigated and resolved. All procedures performed in studies involving human participants were in accordance with the ethical standards of the institutional and/or national research committee(s) and with the Helsinki Declaration (as revised in 2013). Written informed consent was obtained from the patient for publication of this manuscript and any accompanying images.

Open Access Statement: This is an Open Access article distributed in accordance with the Creative Commons Attribution-NonCommercial-NoDerivs 4.0 International License (CC BY-NC-ND 4.0), which permits the noncommercial replication and distribution of the article with the strict proviso that no changes or edits are made and the original work is properly cited (including links to both the formal publication through the relevant DOI and the license). See: https://creativecommons.org/licenses/by-nc-nd/4.0/.

\section{References}

1. Kikkawa T, Kanzaki M, Isaka T, et al. Complete thoracoscopic S9 or S10 segmentectomy through a pulmonary ligament approach. J Thorac Cardiovasc Surg 2015;149:937-9.

2. Igai $\mathrm{H}$, Kamiyoshihara $\mathrm{M}$, Kawatani $\mathrm{N}$, et al. Thoracoscopic lateral and posterior basal $(\mathrm{S} 9+10)$ segmentectomy using intersegmental tunnelling. Eur J Cardiothorac Surg 2017;51:790-1.

3. Sato M, Murayama T, Nakajima J. Thoracoscopic staplerbased "bidirectional" segmentectomy for posterior basal segment (S10) and its variants. J Thorac Dis. 2018;10:S1179-86.

4. Endoh M, Oizumi H, Kato H, et al. Posterior approach to thoracoscopic pulmonary segmentectomy of the dorsal basal segment: A single-institute retrospective review. J Thorac Cardiovasc Surg 2017;154:1432-9.
Cite this article as: Zhang $\mathrm{M}, \mathrm{Wu} \mathrm{QC}, \mathrm{Ge} M \mathrm{MJ}$. Thoracoscopic electrocautery-based bidirectional S9-10 segmentectomy. Transl Cancer Res 2020;9(2):1303-1306. doi: 10.21037/tcr.2020.02.01 